\title{
El síndrome de Epimeteo, Occidente la cultura del olvido
}

\section{Diego Quintana de Uña}

Editorial Cuarto Propio, Santiago de Chile, 2004, 321 págs.

\section{Laura Rodríguez Negrete*}

Recibida: 03.06.2009

Aceptada: 01.07.2009

$* * *$

Si de verdad somos una cultura heredera de los griegos, entonces Diego Quintana de Uña sería el Pitias moderno, donde su libro “El Síndrome de Epimeteo, Occidente la cultura del olvido” podría interpretarse como una suerte de oráculo de Delfos contemporáneo ${ }^{1}$. Es fascinante e inquietante al mismo tiempo, la maestría con que el autor elabora una secuencia teorética a partir de lo que él denomina el "pensamiento único”, evidenciando en el trayecto, la recurrencia permanente de las crisis económicas. De la misma manera que los antiguos griegos utilizaban el oráculo para predecir el futuro, esta obra da cuenta de la tremenda importancia que posee vaticinar la recurrencia de la crisis financieras, tal cual como si estuviéramos frente a un oráculo moderno. Esto último lejos de tranquilizarnos como civilización (consolidando una idea de futuro), nos alarma, debido a la inquietante certeza de estar subordinados a gobiernos, que aun cuando tienen conocimiento de las crisis a priori, hacen poco o nada para evitarlas.

Lo anterior nos lleva a plantearnos las mismas interrogantes que se hace Diego Quintana en su libro y discutir si verdaderamente vamos progresando o en su lugar estamos en una ruta de colisión como él anuncia en su libro. A mi me parece que es más bien lo segundo y a partir de una breve conceptualización de la autonomía como valor amerindio y de la creciente dependencia de los sistemas económicos políticos y sociales de este continente, pretendo establecer que al igual que la cultura occidental -evidenciado en el libro estudiado- estamos en un retroceso, cuya condición podría

\footnotetext{
*Universidad Austral de Chile, Valdivia, Chile. Email: lrodriguez@uach.cl

${ }^{1}$ El oráculo de Delfos fue un recinto sagrado dedicado principalmente al dios Apolo que tenía en el centro un gran templo, al que acudían los griegos para preguntar a los dioses sobre materias urgentes de consideración. Situado en Grecia, en el emplazamiento de lo que fue la antigua ciudad llamada Delfos, al pie del monte Parnaso.
} 
ser circunstancial o constante. Característica que sólo podrá ser definida en el futuro, quizás mediante la exploración de nuestras propias leyendas.

Diego Quintana de Uña, propone evaluar la cultura Occidental en función de las pretensiones originales de esta cultura. De esta manera el autor subraya que para poder iluminarnos acerca de los ideales contemporáneos, es fundamental revisar los principios fundantes del paradigma clásico griego.

La Amerindia por su parte, habría tenido, según yo creo, otras razones transformadoras de la civilización, las cuales se vieron afectadas por la herencia de siglos de invasión y conquista militar y cultural europea. En este sentido, para la cultura mapuche, el fin del ser humano es concluir un camino permitiendo conquistar el conocimiento en sus cuatro formas; la creatividad, la imaginación, la intuición y la comprensión. Si el individuo logra cumplir con esta meta, alcanza el conocimiento de su propio ser y de su rol, es decir, se adueña de su propio filew y en la última etapa de su vida terrenal puede convertirse en un Pillán. Lo cual a la luz del libro de Quintana de Uña, concuerda con el principio de individuación propio de la cultura clásica, cuya revisión se hace urgente si es que pretendemos establecer el estado de progreso, de decadencia o de ruta de colisión de nuestra cultura.

Siguiendo esta línea argumentativa, el autor Diego Quintana de Uña, evidencia por medio del Síndrome de Epimeteo, que los ideales y propósitos de la civilización griega clásica han sido sepultados por la ignorancia y el olvido. Siendo herederos de esta cultura, como se nos pretende hacer creer, creo que sería interesante re-examinar la aspiración original de nuestra propia cultura, cuyas características, entre muchas, fue la autonomía. Elemento columnar de la civilización precolombina, el cual quedo enterrado bajo siglos de invasiones y conquistas, sustituyéndose la autonomía por la dependencia. En un aspecto más profundo, la dependencia se convirtió en una transcripción inerte de los valores y productos de otras culturas; evidenciando en el camino la ausencia de creatividad, imaginación, truncando la intuición y limitando la comprensión del mundo que nos rodea.

Para nadie es un secreto la laboriosidad con que los indígenas de nuestra tierra forjaban su propia autonomía, de otra manera habrían perecido a merced de las inclemencias de un territorio implacable. Su incipiente organización social, era como la palabra lo dice, demasiado elemental para hacerlo dependiente de otras estructuras paralizantes de sus ingentes esfuerzos de sobrevivencia, un buen trozo de tierra donde cultivar y poder criar un ganado era más que suficiente. Para el caso de los más australes, una canoa era un equipamiento rudimentario para asegurar la vida y sus pormenores. Un terreno rodeado de bosques, donde existiera un claro, bastaba para realizar una plegaria a los dioses protectores. Los mapuches nunca construyeron templos, y el Rehue y el Küel fueron las únicas señales edificadas observadas en el paisaje sagrado. 
En nuestro sistema vulnerable y dependiente de las malas prácticas de los países poderosos, anidan los “capitales golondrinas” como lo denomina Quintana de Uña. Todo esto apoyado por los grupos poderosos del G7, el Fondo Monetario Internacional, el Banco Mundial, los cuales una vez desatada la crisis hipotecaria Subprime ${ }^{2}$, responden prontamente el llamado de sus vástagos urdiendo artimañas para desenredar la madeja financiera y evitar el colapso de una economía de la codicia non stop. De esta manera, las autoridades económicas, tratando de evitar el colapso de un sistema alentado por ellas, han optado por diferentes soluciones, entre estas; inyectar dinero desde los bancos centrales de cada país o intervenir y nacionalizar la banca privada.

Las medidas parecen tener como objetivo recuperar la confianza en el sistema, no obstante el consenso tácito es que este capitalismo financiero es una espada de Damocles que pende en la base del sistema financiero internacional. Entonces me pregunto, ¿̇por qué desean que el individuo recupere la confianza en el sistema?

Por otra parte, el autor nos alerta acerca de este consumidor, agente fundamental en esta maquina global, quien imagina dominar el mundo a través de la compra y venta en el mercado financiero. Aquí los bienes de antaño han dado paso "al bien no-bien por excelencia, que es el dinero". Como no creerlo si estas empresas transnacionales compran las acciones del mundo con el dinero de ciudadano común, quien en este comensalismo virtual cree ser parte de una elite, cuando en realidad no es más que un instrumento del juego hegemónico global En este juego de casino, donde de acuerdo al autor, todos creen que van a hacer dinero fácil, se verifica una vez más la profecía anunciada por el autor.

Es verdaderamente aterradora la manera como en este libro se describen los hechos. Cada una de las etapas esta resuelta y escrita a priori, como si el curso de la historia fuera definitivo e indefectible. El desarrollo de los eventos acontecidos en Asia y México hace alrededor de 10 años atrás, da cuenta de una cierta recurrencia, que al menos debiera servir para tomar algunas lecciones futuras. Claro esta que el autor dice que la civilización occidental esta condenada a repetir el error de Epimeteo, cuya esencia nos lleva a vivir continuamente las mismas calamidades históricas.

Este autor establece que para la razón del mundo moderno, la ilusión más presuntuosa es asociar el entendimiento del mundo con el poder sobre él. Y lo que es más perturbador, es la advertencia de que la posesión del dinero también nos da dominio sobre la realidad. En este sentido, volver a nuestras raíces amerindias, donde el proyecto humano perseguía conquistar el conocimiento mediante sus cuatro formas; la creatividad, la imaginación, la intuición y la comprensión del mundo que nos rodea, permite entregar un sentido más profundo a la existencia, como también replantearnos nuestros propósitos como sociedad en conjunto.

Esto último no necesariamente significa retroceder al pensamiento 
dualista moderno, dividiendo cartesianamente a las civilizaciones en buenas y malas, o en su defecto, civilizaciones cuyos pilares se basan en la materia o las que privilegian la búsqueda de la conciencia, se trata más bien de aprender acerca de los olvidos como establece el autor. 